Research Article

\title{
Improved Model for Generating Incremental Product Innovation Schemes
}

\author{
Lisha Geng $\mathbb{D}^{1},{ }^{1}$ Jinge Xing $\mathbb{D}^{2},{ }^{2}$ Xiaofei Shi, ${ }^{1}$ Liran $\mathrm{Zu},{ }^{1}$ and Meiqun Chai ${ }^{1}$ \\ ${ }^{1}$ School of Business Administration, Hebei University of Economics and Business, Shijiazhuang, China \\ ${ }^{2}$ Public Basic Teaching Department, Zhengding Advanced Normal College of Hebei, Shijiazhuang, China \\ Correspondence should be addressed to Jinge Xing; babyxing09@sina.com
}

Received 20 February 2021; Revised 10 July 2021; Accepted 3 August 2021; Published 2 September 2021

Academic Editor: Denis Benasciutti

Copyright (c) 2021 Lisha Geng et al. This is an open access article distributed under the Creative Commons Attribution License, which permits unrestricted use, distribution, and reproduction in any medium, provided the original work is properly cited.

To realize incremental product innovation, the key problems of existing products need to be identified and solved with feasible innovation schemes. This study examines the generation process of innovation schemes by integrating Quality Function Deployment (QFD) and the Theory of Inventive Problem Solving (TRIZ). This study has the following advantages: first, this study proposes new rules for distinguishing physical conflicts with technical conflicts and the method for calculating conflict importance after building House of Quality (HoQ) in QFD. Second, an improved integrated model of QFD and TRIZ is constructed, which generates innovation schemes by solving not only the conflicts between technical characteristics but also the problems of product parts. Third, the uncertainty and subjectivity of the data provided by decision-makers in the evaluation process of innovation schemes are processed by interval grey numbers. Moreover, a cone model is built to make the evaluation results more reliable. Last, a case study of water purifiers is conducted to illustrate the validity of the generation process of incremental product innovation schemes.

\section{Introduction}

In fierce competition, an innovation which brings competitive power is an essential path to develop enterprises and nations. Most innovations (approximately 70\%) are incremental [1]. Based on the current technology, incremental innovation accomplishes minor changes for the current products [2], so products can stay in the market sustainably [3]. Incremental product innovation has a close relationship with customer requirements and will inevitably fail when customer requirements are ignored [4]. For example, in China, a washing machine without a washing powder ignores customers' actual needs, thereby failing incremental innovation [5].

Therefore, finding and solving the problems of existing products while considering customers' requirements are the key problems to be solved to realize incremental product innovation. Driven by customers' requirements, many problems are generally found in our products. Therefore, the concept of importance is introduced to measure these problems to ensure that the problems we solve can meet customers' requirements to a greater extent.

Quality Function Deployment (QFD) is an effective product design method. After obtaining customer requirements, QFD inputs these requirements into the production process through matrices [6]. Altshuller proposed the Theory of Inventive Problem Solving (TRIZ) based on the principles of technological evolution. The TRIZ helps designers to quickly locate the direction of conflict resolution and generate innovative ideas [7]. In TRIZ, different types of conflicts are solved using different tools. For example, for technical conflicts, the suitable invention principle is identified through the contradiction matrix to indicate the direction of product innovation.

Although the literature on the integration model of QFD and TRIZ has been extending, some problems still need to be solved for the generation of incremental product innovation schemes. Hence, we build an improved model with QFD and TRIZ and attempt to address the following research questions: 
RQ1: How to distinguish the technical conflicts and physical conflicts in the House of Quality (HoQ), calculate their importance, determine the key problems to be solved based on their importance, and then generate innovation schemes based on the tools and methods of TRIZ?

RQ2: How to measure the feasibility of innovation schemes and identify the most feasible innovation scheme?

The remainder of this paper is organized as follows. Section 2 provides a full review of incremental innovation and the integration of QFD and TRIZ. Section 3 proposes the generation of incremental product innovation schemes. Section 4 presents a case study of water purifiers to demonstrate the validity of the integrated model. Section 5 makes a comparative analysis and discussion. Finally, Section 6 concludes the study.

\section{Literature Review}

2.1. Incremental Innovation. Incremental innovation is achieved by refining the potential of established products based on existing technology or knowledge by improving the production process, efficiency, quality, and market matching degree; reducing costs; and other ways [8]. The purpose of incremental innovation is to fully meet the requirements of the current and potential customers. Thus, incremental innovation is an innovation oriented toward customer requirements [9]. We should consider the driving role of customer requirements to ensure that incremental product innovation does not depart from customer requirements.

The unique characteristic of incremental product innovation is that it improves the products through low risk and high feasibility while considering customer requirements $[10,11]$. In the process of achieving incremental product innovation, on the one hand, we need to identify and solve the conflicts of product technology with the existing technology from the intangible perspective. On the other hand, we need to improve raw materials, functions, or structures of product parts from the tangible perspective.

2.2. Integration of $Q F D$ and TRIZ. QFD is a product planning technology driven by customer requirements and deploys such customer requirements into the product design process through a series of matrices [12]. In the first stage of QFD, HoQ is the most commonly used matrix, as shown in Figure 1.

This matrix consists of four parts: "wall," "room," "roof," and "basement" [13]. The "wall" consists of customer requirements and their importance, and the "room" consists of the relationship matrix between customer requirements and technical characteristics. Then, the "roof" consists of technical characteristics and its correlation matrix, and the basement consists of the importance of technical characteristics.

On the "roof" of HoQ, "+" is used to indicate the positive correlation between two technical characteristics. That is, an improvement of one technical characteristic causes the

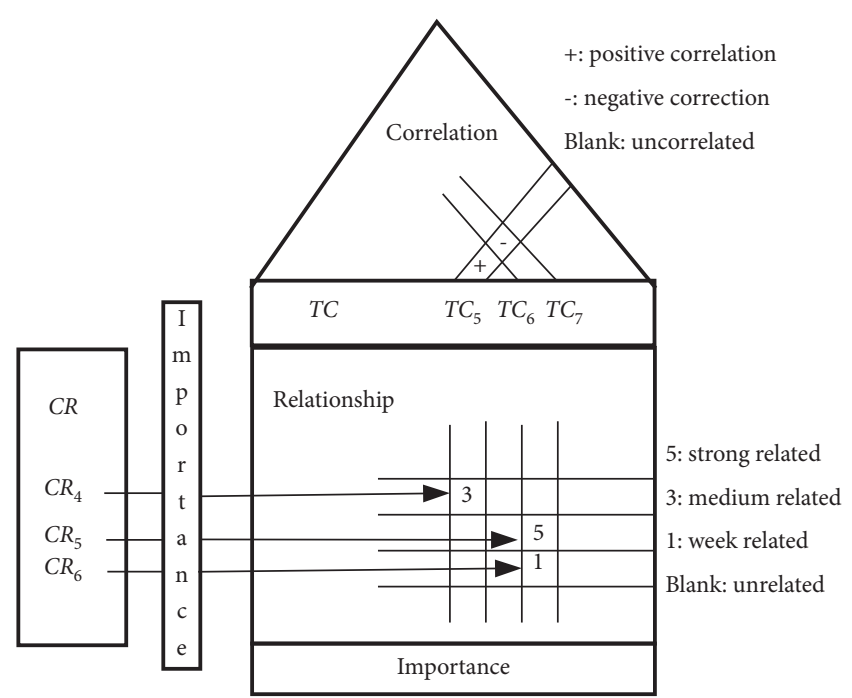

Figure 1: House of quality.

improvement of the other. Then, “-” is used to indicate the negative correlation between two technical characteristics. That is, an improvement of one technical characteristic causes the deterioration of the other. This notion indicates the conflicts between technical characteristics of products. Conflicts inevitably exist in the process of product innovation, which usually represent the difficulties and technical bottlenecks of product innovation. A process that does not resolve conflicts cannot be called the process of innovation [14].

The previous integration model of QFD and TRIZ used the contradiction matrix of TRIZ to deal with the technical conflicts between negatively related technical characteristics $[15,16]$. However, this integrated model only identifies the technical conflicts between the technical characteristics, and the physical conflicts and the product parts that need to be improved are ignored. Hence, we propose the improved integration model with QFD and TRIZ in this research. On the one hand, the rules to distinguish technical and physical conflicts between technical engineering and the methods to calculate their importance are proposed. On the other hand, the problems of key parts are determined and solved based on the importance of the QFD output with the Su-Field model in TRIZ.

\section{Generation of Incremental Product Innovation Schemes}

To solve the conflicts of product technology, improve product parts, and point out the direction of incremental product innovation, an improved integration model of QFD and TRIZ is constructed, as shown in Figure 2. CR, TC, and $\mathrm{PC}$ represent customer requirement, technical characteristic, and part characteristic, and $W_{\mathrm{CR}}, W_{\mathrm{TC}}$, and $W_{\mathrm{PC}}$ represent their importance, respectively. Compared with previous studies, the improved model has the following advantages. First, the rules for distinguishing technical and physical conflicts in the "roof" of HoQ are proposed. Second, the methods for calculating the importance of conflicts are 
proposed, which present the basis for identifying key conflicts. Third, Su-Field models and the standard solutions of TRIZ are used to identify and solve the problems of key parts. These key parts are determined based on the importance of part output in the second stage of QFD. Fourth, the improved model realizes incremental product innovation from tangible and intangible perspectives, so the bottlenecks of technologies and the problems of product parts are identified and solved.

3.1. Identification and Resolution of Key Conflicts. According to TRIZ, two kinds of conflicts are identified: technical and physical conflicts. Each kind of conflict has corresponding solutions. In this part, the rules of distinguishing the technical and physical conflicts between technical characteristics in the "roof" of HoQ and the methods for calculating their importance are proposed.

3.1.1. Identification and Resolution of Key Physical Conflicts. A physical conflict includes the following elements: an object, requirement $A$ that the object satisfies, and requirement $-A$ that the object does not satisfy. $A$ is opposite to $-A$.

According to the definitions of physical conflicts, physical conflicts between technical characterizations have two kinds.

In the first kind, technical characteristic $i$ is positively correlated with technical characteristic $j$. Meanwhile, technical characteristic $j$ is negatively correlated with technical characteristic $k$. The improvement of technical characteristic $j$ will cause the improvement of technical characteristic $i$ and the deterioration of technical characteristic $k$ simultaneously. For example, simply prolonging the filter replacement cycle of the water purifier with existing technology can reduce the maintenance fee, but the purification effect of the water purifier will also be reduced. That is to say, on the one hand, the filter replacement cycle needs to be prolonged to reduce the maintenance fee. On the other hand, the filter replacement cycle cannot be prolonged to avoid the deterioration of the purification effect. Therefore, a physical conflict exists among the three technical characteristics, namely, the purification effect, filter replacement cycle, and maintenance fee.

Rule 1 is proposed to identify the first kind of physical conflict.

Rule 1. Suppose technical characteristics in $\mathrm{HoQ}$ are denoted as $\mathrm{TC}_{1}, \mathrm{TC}_{2}, \ldots, \mathrm{TC}_{n}$. $W_{i}$ denotes the importance of technical characteristic $i$, and $C(i, j)$ denotes the correlation between technical characteristics $i$ and $j$. When $C(i, j)$ is larger than 0 , a positive correlation exists between technical characteristics $i$ and $j$. When $C(i, j)$ is less than 0 , a negative correlation exists between them. Thus, if

$$
C(i, j) * C(j, k)<0, \quad i, j, k=1,2, \ldots, n,
$$

then physical conflicts exist among technical characteristics $i, j$, and $k$.
In the second kind, when technical characteristics with negative correlation are attributed to different aspects of the same technical characteristic, physical conflicts exist between the technical characteristics.

For example, when buying a house, the down payment for the house is negatively correlated to the loan. The two technical characteristics are the cost of buying a house. They represent two different aspects of the same technical characteristic. Rule 2 is proposed to identify the second kind of physical conflict.

Rule 2. When technical characteristics $i$ and $j$ are attributed to different aspects of the same technical characteristic, if

$$
C(i, j)<0, \quad i, j=1,2, \ldots, n,
$$

then physical conflicts exist between technical characteristics $i$ and $j$.

To identify the key conflicts, the conflict's importance, denoted by $W_{C}$, is calculated in equations (3) and (4) according to the importance of the corresponding technical characteristics that are calculated under the drive of customer requirements. The reason is that in QFD, the importance of technical characteristics depended on the importance of customer requirements and the relationship between customer requirements and technical characteristics. Then, the separation principles of TRIZ are used to resolve the key physical conflicts.

$$
\begin{gathered}
W_{C(i, j, k)}=\left(\frac{W_{i}^{2}+W_{j}^{2}+W_{k}^{2}}{3}\right)^{1 / 2}, \quad i, j, k=1,2, \ldots, n, \\
W_{C(i, j)}=\left(\frac{W_{i}^{2}+W_{j}^{2}}{2}\right)^{1 / 2}, \quad i, j=1,2, \ldots, n .
\end{gathered}
$$

\subsubsection{Identification and Resolution of Technical Conflicts.} Technical conflict refers to the product's characteristics resulting in useful and harmful results. Technical conflict also refers to the introduction of useful effects or the elimination of harmful effects resulting in the deterioration of one or more subsystems or systems [17]. Technical conflicts usually involve two parameters: $A$ and $B$. The improvement of $A$ will cause the deterioration of $B$. For example, the expansion of a house's area will lead to an increase in the price. A technical conflict exists between the two technical characteristics: a house's area and price. When technical characteristic $i$ is negatively related with technical characteristics $j$, and they are not attributed to two different aspects of one technical characteristic, a technical conflict exists between the two technical characteristics. Its importance is calculated in equation (4). The contradiction matrix is used to analyze the corresponding improved and deteriorated characteristics, and then, related invention principles are used to solve the conflict. 


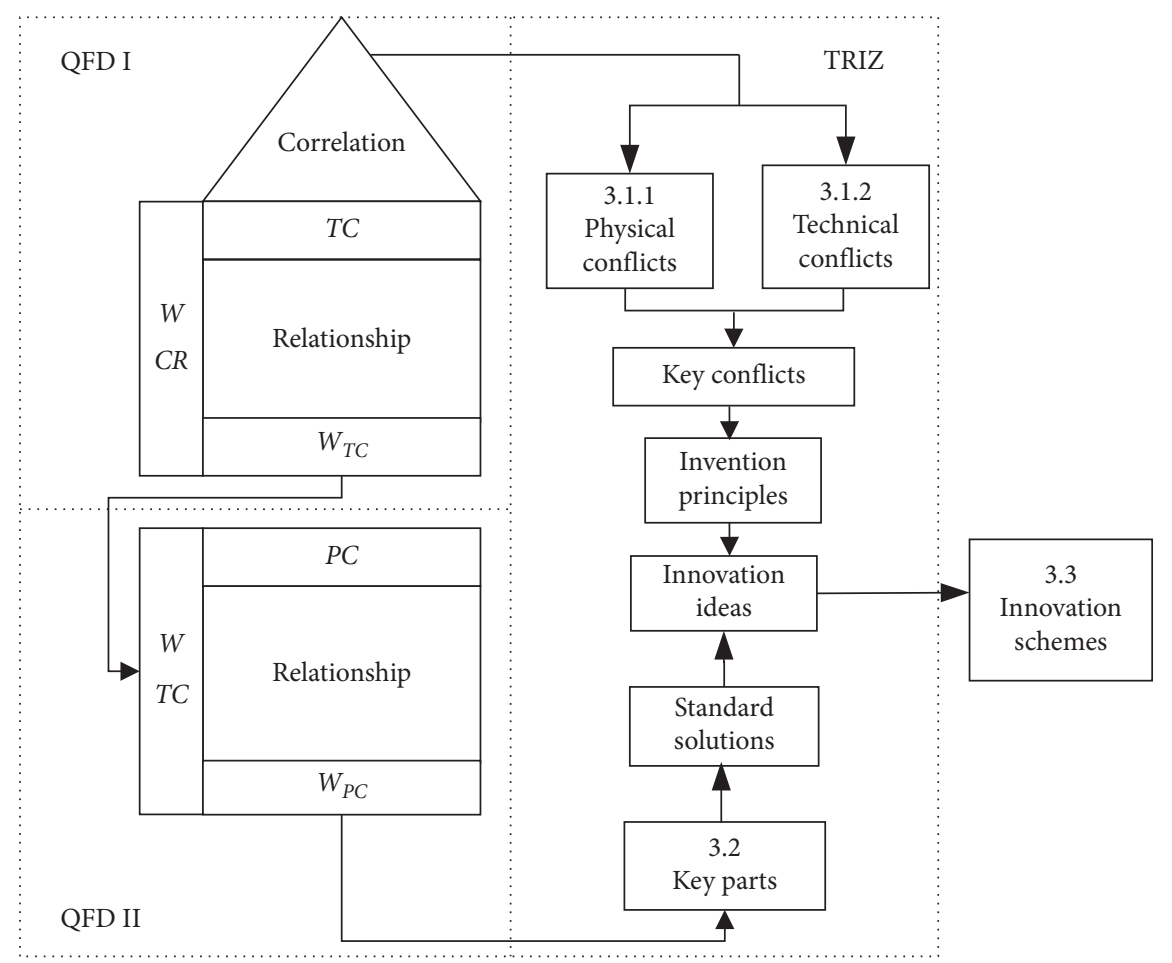

FIGURE 2: Improved model for generating incremental product innovation schemes.

3.2. Identification and Resolution of the Problems of Key Parts. In addition to conflicts in technology, the problems of product parts also need to be solved to accomplish incremental product innovation. The improved model uses the Su-Field models of TRIZ to analyze the key parts which are determined by the importance of part characteristic output in the second stage of QFD. For example, the RO membrane is identified as the most important part of the water purifier after the calculation with QFD in the case study. The SuField for the RO membrane is built to analyze its problem, and standard solutions are used to improve it. This model aims to accomplish incremental product innovation by improving the product's parts, such as adding new features, improving the material, and changing the structure of parts. The Su-Field model is used to describe the internal structure of a system. By building the Su-Field model, the problems of parts are analyzed, and then, 76 standard solutions are used to generate incremental product innovative ideas.

3.3. Evaluation of Innovation Schemes. Based on the invention principles and standard solutions of TRIZ, innovative ideas are generated, which usually form multiple innovation schemes. However, considering the constraints of realistic conditions, the feasibility of innovation schemes should be evaluated from multiple attributes to choose the most feasible one.

In the research of multiattribute decision-making evaluation, scholars mainly studied the processing of the uncertainty of data and the set of attribute weights. Professor Wan used Pythagorean fuzzy numbers and Atanassov's interval-valued fuzzy values to deal with the uncertainty of data $[18,19]$. In dealing with the weight of attributes, biobjective and multiobjective mathematical programming models are built to calculate the weights objectively $[19,20]$. These studies effectively dealt with the problems in multiattribute evaluation decision-making. In this study, interval grey numbers are used to deal with the inadequacy and uncertainty of data provided by experts. The final weights of the scheme's attributes are calculated by combining objective and subjective weights that are calculated through Grey Relational Analysis (GRA) and the Delphi method, respectively. The closeness of attributes is calculated using the Technique for Order of Preference by Similarity to Ideal Solution (TOPSIS). The closeness and weights of innovation schemes' attributes, which are taken as the height and the radius, respectively, are integrated into a cone model to evaluate the feasibility of innovation schemes. Figure 3 depicts the calculation process.

Deng, a Chinese scholar, founded the grey system theory [21], which can deal with inadequate, incomplete, and uncertain problems of data. The evaluation data of innovation schemes provided by experts are usually inadequately limited by the number of experts. Hence, interval grey numbers in the grey system theory, represented by upper and lower bounds, are used to evaluate the innovation schemes.

Definition 1. Suppose two interval grey numbers exist: $\otimes \alpha$ and $\otimes b$.

$$
\begin{aligned}
\otimes a & =[\underline{a}, \bar{a}], \\
\otimes b & =[\underline{b}, \bar{b}] .
\end{aligned}
$$




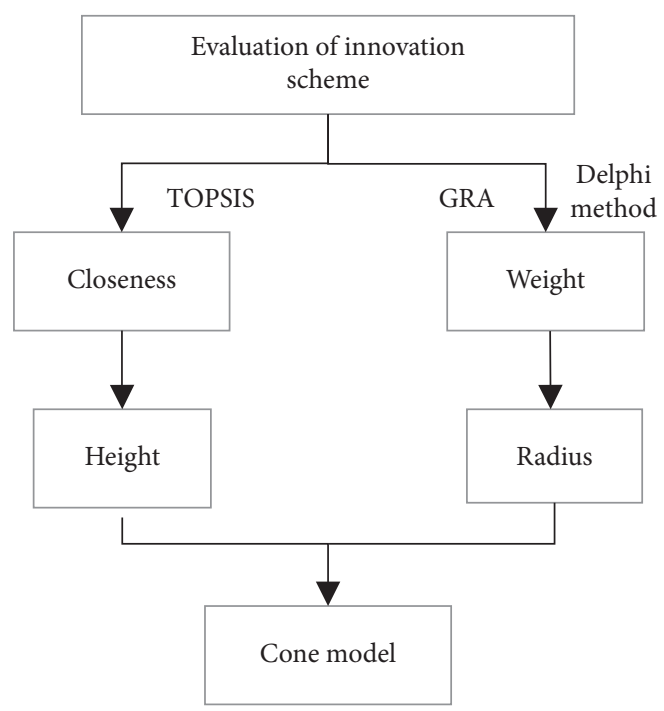

FIGURE 3: Evaluation process of innovation schemes.

The distance between the two interval grey numbers, denoted as $L$, is calculated as follows [22]:

$$
L=\left[(\underline{a}-\underline{b})^{2}+(\bar{a}-\bar{b})^{2}\right]^{1 / 2} \text {. }
$$

Matrices $A_{1}, A_{2}, \ldots, A_{r}$ are formed with the evaluation data provided by $r$ experts. Matrix $B$ is formed by combining the evaluation data provided by experts in equation (8). $A_{k} \otimes \alpha_{j i}$ denotes the evaluation on the $i$ th attribute of the $j$ th innovation scheme by expert $A_{k}$.

$$
\begin{aligned}
A_{1} & =\left[\begin{array}{cccc}
\otimes a_{11} & \otimes a_{12} & \cdots & \otimes a_{1 m} \\
\otimes a_{21} & \otimes a_{22} & \cdots & \otimes a_{2 m} \\
\vdots & \vdots & \ddots & \vdots \\
\otimes a_{n 1} & \otimes a_{n 2} & \cdots & \otimes a_{n m}
\end{array}\right] A_{2}=\left[\begin{array}{cccc}
\otimes a_{11} & \otimes a_{12} & \cdots & \otimes a_{1 m} \\
\otimes a_{21} & \otimes a_{22} & \cdots & \otimes a_{2 m} \\
\vdots & \vdots & \ddots & \vdots \\
\otimes a_{n 1} & \otimes a_{n 2} & \cdots & \otimes a_{n m}
\end{array}\right], \ldots, A_{r}=\left[\begin{array}{cccc}
\otimes a_{11} & \otimes a_{12} & \cdots & \otimes a_{1 m} \\
\otimes a_{21} & \otimes a_{22} & \cdots & \otimes a_{2 m} \\
\vdots & \vdots & \ddots & \vdots \\
\otimes a_{n 1} & \otimes a_{n 2} & \cdots & \otimes a_{n m}
\end{array}\right], \\
\otimes a_{j i} & =\left[\underline{a}_{j i}, \bar{a}_{j i}\right], \quad i=1,2, \ldots, m ; j=1,2, \ldots, n . \\
\otimes b_{j i} & =\frac{1}{r} \sum_{k=1}^{r} A_{k} \otimes a_{j i}, \quad i=1,2, \ldots, m ; j=1,2, \ldots, n ; k=1,2, \ldots, r .
\end{aligned}
$$

Definition 2. The distance between the $i$ th attribute of the $j$ th innovation scheme and the ideal solution is represented by $d+j i$. $\otimes I$ is used to represent the ideal solution.

$$
d_{j i}^{+}=D\left(\otimes b_{j i}, \otimes I\right), \quad i=1,2, \ldots, m ; j=1,2, \ldots, n .
$$

Definition 3. The distance between the $i$ th attribute of the $j$ th innovation scheme and the negative ideal solution is represented by $d-j i . \otimes N$ is used to represent the negative ideal solution.

$$
d_{j i}^{-}=D\left(\otimes b_{j i}, \otimes N\right), \quad i=1,2, \ldots, m ; j=1,2, \ldots, n .
$$

The closeness of the $i$ th attribute of the $j$ th innovation scheme, denoted as $d_{j i}$, is calculated based on TOPSIS in equation (11). As the value of $d_{j i}$ increases, the scheme becomes better.

$$
d_{j i}=\frac{d_{j i}^{-}}{d_{j i}^{+}+d_{j i}^{-}}, \quad i=1,2, \ldots, m ; j=1,2, \ldots, n .
$$

The objective weight is calculated by GRA. Matrix $X$ is formed after whitening the interval grey number in matrix $A$ with the following equation:

$$
\begin{aligned}
& x=k \underline{a}_{j i}+(1-k) \overline{a_{i i}}, \quad k \in[0,1], i=1,2, \ldots, m \\
& X=\left[\begin{array}{cccc}
x_{11} & x_{12} & \cdots & x_{1 m} \\
x_{21} & x_{22} & \cdots & x_{2 m} \\
\vdots & \vdots & \ddots & \vdots \\
x_{n 1} & x_{n 2} & \cdots & x_{n m}
\end{array}\right] .
\end{aligned}
$$

The optimal value of each attribute is selected in the matrix, denoted as $X_{0}$. 


$$
X_{0}=\left(\begin{array}{llll}
X_{01} & X_{02} & \cdots & X_{0 m}
\end{array}\right) .
$$

$X_{0}$ and $X_{j i}$ are taken as the reference and comparison sequences, respectively. Equation (14) is used to calculate $\xi$, which denotes the grey correlation coefficient of the $i$ th attribute for the $j$ th innovation scheme. $\rho$ denotes the distinguishing coefficient, whose value is usually 0.5 .

$$
\begin{aligned}
\xi_{i j} & =\frac{\min _{i} \min _{j}\left|X_{0 i}-X_{j i}\right|+\rho \max _{i} \max _{j}\left|X_{0 i}-X_{j i}\right|}{\left|X_{0 i}-X_{j i}\right|+\rho \max _{i} \max _{j}\left|X_{0 i}-X_{j i}\right|}, \\
i & =1,2, \ldots, m ; j=1,2, \ldots, n .
\end{aligned}
$$

The correlation between the comparison and reference sequences, denoted by $r_{j}$, is calculated as follows:

$$
r_{i}=\frac{1}{n} \sum_{j=1}^{n} \xi_{j i}, \quad i=1,2, \ldots, m ; j=1,2, \ldots, n .
$$

The objective weight of the attribute, denoted as $W_{i}^{1}$, is calculated as follows:

$$
W_{i}^{1}=\frac{r_{i}}{\sum_{i=1}^{m} r_{i}}, \quad i=1,2, \ldots, m ; j=1,2, \ldots, n .
$$

The subjective weights of attributes provided by experts, denoted as $W_{i}^{2}$, are gained using the Delphi method. The final weight of attributes, which integrates the objective and subjective weights, denoted as $W_{i}$, are calculated as follows [23]:

$$
W_{i}=0.6 * W_{i}^{1}+0.4 * W_{i}^{2}
$$

A cone model is constructed with the final weights and the closeness of the attributes of the innovation schemes, as shown in Figure 4. Equation (18) is used to calculate the conical volumes corresponding to each scheme to select the most feasible scheme. $V$ represents the value of the scheme's feasibility. As $V$ increases, the scheme becomes more feasible.

$$
V_{j}=\frac{\pi}{3} \sum_{i=1}^{m} W_{i}^{2} d_{j i}, \quad i=1,2, \ldots, m ; j=1,2, \ldots, n .
$$

In sum, the steps to identify the most feasible innovation scheme are given as follows:

Step 1. Evaluate the innovation scheme's attributes with interval grey numbers and form the evaluation matrix.

Step 2. Calculate the closeness of the attributes based on TOPSIS in equations (9)-(11) after standardizing the matrix.

Step 3. Calculate the final weights of the attributes in equation (17). The weight combines the objective weights calculated based on GRA in equations (12)-(16) and the subjective weights gained using the Delphi method.

Step 4. Evaluate the innovation schemes based on the volumes of the cones in equation (18).
Previous studies only considered the difference in weights of attributes in the evaluation of innovation schemes and regarded the closeness of all the attributes as the same [24]. That is, in the cone model, a scheme only has the same height. In this study, we consider not only the difference between attribute weights but also the differences of attributes' closeness. Hence, in the cone model, one innovation scheme has more than one height that represents the attribute's different closeness. With this evaluation, we can further effectively evaluate the feasibility of the scheme.

\section{Case Study}

Household RO membrane reverse osmosis water purifiers (hereinafter referred to as water purifiers) are used by many families to purify drinking water in China. However, problems still exist in the process of using water purifiers, which puzzle customers and cause a decrease in customer satisfaction. Therefore, based on customer requirements for improving existing water purifiers, the incremental innovation for water purifiers needs to be realized. With the improved model proposed in this research, the generation of incremental schemes for the incremental innovation of water purifiers is studied. In the first stage of QFD, the HoQ of water purifiers is built. Figure 5 shows the "roof" of the HoQ. Table 1 presents the contents of $\mathrm{TC}_{1}$ to $\mathrm{TC}_{22}$. As the importance of the calculation of customer requirements and technical characteristics is not the focus of this research, this part will not be discussed in detail. The following five steps are used to find and solve the conflicts in technology and part problems for water purifiers .

Step 1. Identify and solve key conflicts in the first phase of QFD.

Key technical and physical conflicts between technical characteristics are identified and resolved in this step. According to Rules 1 and 2, five pairs of conflicts are identified. Equations (3) and (4) are used to calculate the importance of conflicts, respectively. Table 2 shows the results.

Given that $m$ conflicts exist, $W_{i}$ represents the importance of the $i$ th conflict. The importance of key conflict, denoted by $W_{k}$, should satisfy the condition in the following equation:

$$
W_{k}>\frac{1}{m} \sum_{i=1}^{m} W_{i}, \quad i=1,2,3, \ldots, m .
$$

According to the calculation results, the first three conflicts are identified as the key conflicts. Invention principles are used to solve the conflicts, as shown in Table 3.

Step 2. Improve key components in the second phase of QFD

The problems of key product parts are identified and resolved in this step.

According to the output information in the first stage of QFD, the matrix of technical characteristics and part 


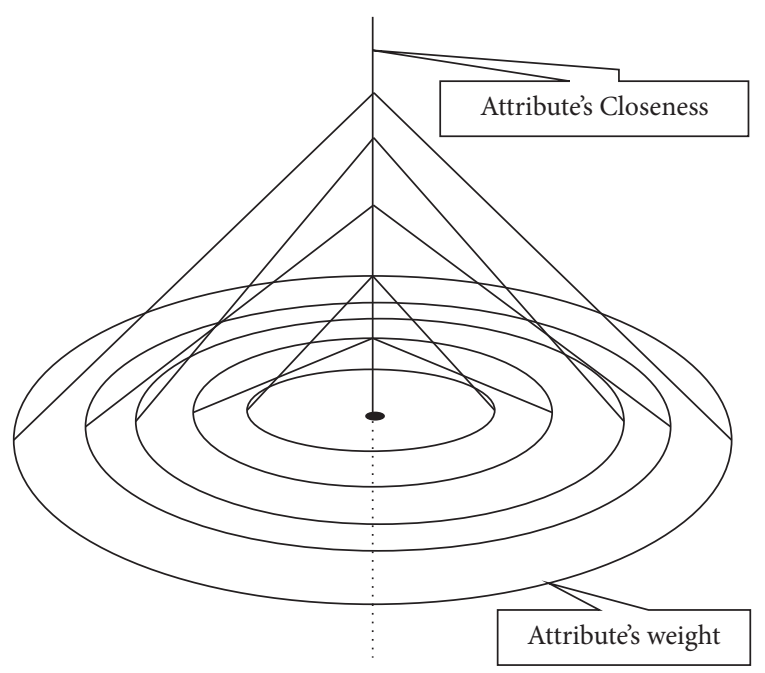

Figure 4: Cone model for the evaluation of innovation schemes.

characteristics in the second stage of QFD is built. The importance of part characteristics is calculated with the calculation method proposed by Geng et al. [25]. Table 4 presents the calculation results of parts' importance. Given that $n$ parts exist, $W_{j}$ represents the importance of the $j$ th part. The importance of the key part, denoted by $W_{k}$, should satisfy the condition in equation (20). Therefore, the RO membrane, filter element, booster pump, and water-quality detection table are regarded as key parts that need to be improved.

$$
W_{k}>\frac{1}{n} \sum_{j=1}^{n} W_{j}, \quad j=1,2,3, \ldots, n .
$$

The Su-Field model is established to find the problems of the key parts. Standard solutions are used to solve the problems, taking the analysis process of the RO membrane as an example. Figure 6 shows the Su-Field model for the RO membrane.

$S_{1}$ : RO membrane; $S_{2}$ : tap water; $F$ : mechanical field; $U$ : useful substance; and $H$ : useless substance.

Based on the Su-Field model of RO membrane, during the purification process of water purifiers, the RO membrane produces much-concentrated water that is undrinkable. However, blindly reducing the wastewater discharge of the $\mathrm{RO}$ membrane will lead to membrane blockage and affect the service life of the membrane. Hence, the following three standard solutions of TRIZ are selected to improve the $\mathrm{RO}$ membrane.

According to Standard Solution No. 11 in the first category, a harmful effect is caused by a field, and thus, substance $S_{3}$ is introduced to absorb the harmful effect. Although the concentrated water discharged by the water purifier cannot pass through the RO membrane, the water through the filtration of the first three filters is still cleaner than tap water. Therefore, a water storage tank can be installed to avoid waste of concentrate water, and also, the service life of the $\mathrm{RO}$ membrane is not shortened.
According to Standard Solution No. 12, useful and harmful effects coexist in a system, but $S_{1}$ and $S_{2}$ must be in contact. Field $F_{2}$ is added to offset the effect of $F_{1}$. A kind of light field is added, and a photocatalytic reaction is applied to mineralize bacterial viruses, such as microorganisms. Thus, heavy metals are detoxified, and water is pretreated before entering the RO membrane to improve its permeability.

According to Standard solution No. 37 in the third category, the system is converted into dual or multiple systems. The traditional single-membrane water purifier is replaced by a double-RO membrane water purifier. The concentrated water produced by the first RO membrane is repurified by the second RO membrane and then through the ultrafiltration membrane. Therefore, the concentrated water can be reused.

Step 3. Form innovation solutions.

Innovation schemes are formed by integrating innovative ideas generated based on invention principles and standard solutions of TRIZ.

Scheme 1. Prefilter is added to pretreat tap water to effectively absorb solid particles, such as sediment and debris. The filter core is designed as an irregular structure, and the guide plate is added to allow raw water to enter the filter core from different directions and improve the utilization rate of the filter core. The pressure of the booster pump and the diaphragm of the $\mathrm{RO}$ membrane are increased to effectively improve the water yield of the RO membrane and realize the function of ready-made drinking without changing the original water flow rate. The original water storage bucket of the water purifier is changed into a concentrated water storage bucket, and the concentrated water is reused as domestic water. Moreover, the TDS detection module is installed at the outlet of the water purifier to detect the effect of water purification in real time.

Scheme 2. Double membranes and double systems are applied. First, an energy photocatalytic reaction is collected to mineralize microorganisms and detoxify heavy metals. Second, a two-stage RO membrane filtration system is used to circulate raw water and reduce wastewater discharge. The pump is installed before the first filter element, so the filter element and RO membrane are washed forward and backward through a larger water pressure to prolong the service life of the pump. A TDS detection module is installed at the outlet.

Scheme 3. Existing cylindrical filter element is designed as a rotatable curved filter element to extend the water filtration path. The inlet of the $\mathrm{RO}$ membrane deviates from the central axis of the membrane shell. When water enters the inner of the filter core, a larger water flow is generated, which affects the nonaqueous substances attached to the surface of the membrane and cleans the membrane during the water-making process to prolong the life of the membrane. The RO membrane 
wastewater pipe is connected with the domestic water pipe to reuse the wastewater without discharging. The direction of membrane water intake is changed from one-way to two-way to improve the utilization rate of the membrane, and a TDS detection module is installed at the outlet.

Step 4. Evaluate innovation schemes.

The three innovation schemes are evaluated based on the method proposed in Section 3.3. The feasibility of every scheme is evaluated from four attributes, that is, the feasibility in the development cycle, cost, antirisk, and implementation. The expert group is composed of a technical researcher, a water purifier manager, and a water purifier after-sales technician. The interval grey number between 0 and 1 is used by experts for evaluation. $A_{1}, A_{2}$, and $A_{3}$ are the evaluation matrices provided by the three experts.

$A_{1}=\left\{\begin{array}{cccc}{[0.7,0.8]} & {[0.8,0.9]} & {[0.7,0.8]} & {[0.8,1]} \\ {[0.4,0.5]} & {[0.5,0.6]} & {[0.6,0.7]} & {[0.4,0.5]} \\ {[0.6,0.7]} & {[0.4,0.5]} & {[0.3,0.4]} & {[0.2,0.3]}\end{array}\right\}$,

$A_{2}=\left\{\begin{array}{llll}{[0.5,0.6]} & {[0.5,0.7]} & {[0.6,0.8]} & {[0.7,0.9]} \\ {[0.4,0.5]} & {[0.2,0.3]} & {[0.3,0.5]} & {[0.3,0.4]} \\ {[0.3,0.4]} & {[0.3,0.5]} & {[0.4,0.5]} & {[0.1,0.2]}\end{array}\right\}$,

$A_{3}=\left\{\begin{array}{cccc}{[0.8,0.9]} & {[0.5,0.6]} & {[0.7,0.8]} & {[0.8,0.9]} \\ {[0.2,0.3]} & {[0.3,0.4]} & {[0.3,0.45]} & {[0.25,0.4]} \\ {[0.85,0.9]} & {[0.45,0.6]} & {[0.2,0.3]} & {[0.5,0.6]}\end{array}\right\}$.

(21)

Matrix $B$ is obtained by combining the evaluation data with equation (8):

$B=\left\{\begin{array}{llll}{[0.67,0.77]} & {[0.60,0.73]} & {[0.67,0.80]} & {[0.77,93]} \\ {[0.33,0.43]} & {[0.33,0.43]} & {[0.40,0.55]} & {[0.32,0.43]} \\ {[0.58,0.67]} & {[0.38,0.53]} & {[0.30,0.40]} & {[0.03,0.37]}\end{array}\right\}$.

Interval grey numbers $[1,1]$ and $[0,0]$ are used to represent the ideal and negative ideal solutions, respectively. The closeness of schemes' attributes is calculated in equations (9)-(11). Table 5 shows the results.

According to equations (12)-(16), the objective weights of scheme attributes are obtained. The Delphi method is used to obtain the subjective attribute weights, which are obtained after three rounds of anonymous evaluation and feedback by experts. The final weights of scheme attributes are calculated in equation (17), and Table 6 presents the calculation result.

Step 5. Identify the most feasible innovation scheme.

The most feasible innovation scheme is identified in this step.

Equation (18) is used to evaluate the feasibility of the innovation schemes, and Table 7 shows the results. The feasibility value of Scheme 1 is the largest, so Scheme 1 is the most feasible innovation scheme.

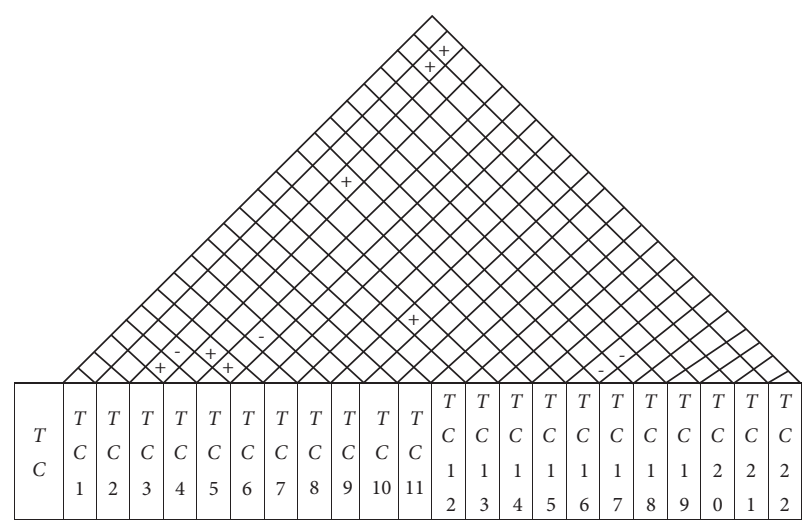

Figure 5: "Roof” of water purifier's HoQ.

TABle 1: Contents of $\mathrm{TC}_{1}$ to $\mathrm{TC}_{22}$.

\begin{tabular}{lc}
\hline $\mathrm{TC}$ & Contents \\
\hline $\mathrm{TC}_{1}$ & Cleaning capacity \\
$\mathrm{TC}_{2}$ & Product life \\
$\mathrm{TC}_{3}$ & Purification effect \\
$\mathrm{TC}_{4}$ & Absorption force \\
$\mathrm{TC}_{5}$ & Filter replacement cycle \\
$\mathrm{TC}_{6}$ & Maintenance fee \\
$\mathrm{TC}$ & Contents \\
$\mathrm{TC}_{7}$ & Security \\
$\mathrm{TC}_{8}$ & Wastewater discharge \\
$\mathrm{TC}_{9}$ & Maintenance times \\
$\mathrm{TC}_{10}$ & Pressure boost \\
$\mathrm{TC}_{11}$ & Power \\
$\mathrm{TC}_{12}$ & Structural complexity \\
$\mathrm{TC}$ & Contents \\
$\mathrm{TC}_{13}$ & Workmanship \\
$\mathrm{TC}_{14}$ & Number of product components \\
$\mathrm{TC}_{15}$ & Purification time \\
$\mathrm{TC}_{16}$ & Power consumption \\
$\mathrm{TC}_{17}$ & Heating capacity \\
$\mathrm{TC}_{18}$ & Refrigeration capacity \\
$\mathrm{TC}_{\mathrm{TC}}$ & Contents \\
$\mathrm{TC}_{19}$ & Volume \\
$\mathrm{TC}_{20}$ & Testing water-quality capability \\
$\mathrm{TC}_{21}$ & \\
$\mathrm{TC}_{22}$ & Automatic cleaning capability \\
\hline
\end{tabular}

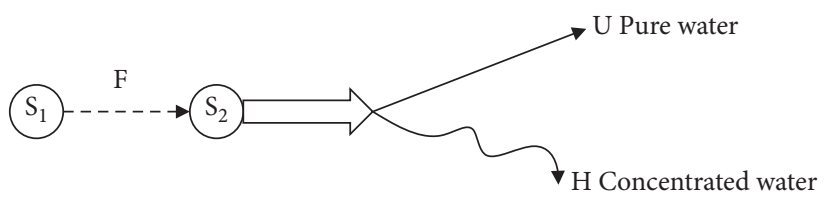

Figure 6: Su-Field model of the RO membrane.

\section{Comparative Analysis and Discussion}

To identify and solve the problems of existing products with the driving of customer requirements, this study constructs 
TABLE 2: Importance of the conflicts of water purifier.

\begin{tabular}{|c|c|c|c|c|c|}
\hline No. & Technical characteristics & Type of conflicts & Importance of conflicts & Weight & Cumulative percentage (\%) \\
\hline 1 & $\begin{array}{l}\mathrm{TC}_{8} \\
\mathrm{TC}_{5} \\
\end{array}$ & Technical conflict & 5.96 & 0.40 & 40.10 \\
\hline 2 & $\begin{array}{l}\mathrm{TC}_{5} \\
\mathrm{TC}_{3}\end{array}$ & Technical conflict & 3.28 & 0.22 & 62.20 \\
\hline 3 & $\begin{array}{l}\mathrm{TC}_{5} \\
\mathrm{TC}_{6} \\
\mathrm{TC}_{3} \\
\end{array}$ & Physical conflict & 3.27 & 0.22 & 84.22 \\
\hline 4 & $\begin{array}{l}\mathrm{TC}_{16} \\
\mathrm{TC}_{17} \\
\end{array}$ & Technical conflict & 1.17 & 0.07 & 92.11 \\
\hline 5 & $\begin{array}{l}\mathrm{TC}_{16} \\
\mathrm{TC}_{18}\end{array}$ & Technical conflict & 1.17 & 0.07 & 100.00 \\
\hline
\end{tabular}

TABLE 3: Analysis of conflicts.

\begin{tabular}{lcc}
\hline No. of conflicts & Corresponding engineering parameters & No. of invention principles \\
\hline 1 & $\mathrm{TC}_{8} \longrightarrow$ No. 31 harmful factors caused by objects & 22 \\
\hline 2 & $\mathrm{TC}_{5} \longrightarrow$ No. 16 effect time of stationary objects & 20, 10, 16, 38 \\
\hline & $\mathrm{TC}_{5} \longrightarrow$ No. 16 effect time of stationary objects \\
3 & $\mathrm{TC}_{3} \longrightarrow$ No. 39 productivity & No. 16 effect time of stationary objects \\
& $\mathrm{TC}_{6} \longrightarrow$ No. 31 harmful factors caused by objects & Separation of time: L9, 10, 11, 15, 16, 18, 19, 20, 21, 29, 34, 37 \\
\hline
\end{tabular}

TABLE 4: Importance of part characteristics.

\begin{tabular}{lcc}
\hline PC & Importance & Rank \\
\hline RO membrane & 5.3335 & 1 \\
Filter & 5.0000 & 2 \\
Booster pump & 4.6665 & 3 \\
Water quality detection table & 3.0000 & 4 \\
Pressure barrel & 2.1170 & 5 \\
Induction device & 2.1100 & 6 \\
Display panel & 2.1056 & 7 \\
RO membrane shell & 2.0565 & 8 \\
Filter barrel & 1.8961 & 9 \\
Heating pipe & 1.8892 & 10 \\
Cooling compressor & 1.8885 & 11 \\
Flushing solenoid valve & 1.8814 & 12 \\
Gooseneck faucet & 1.1377 \\
\hline
\end{tabular}

TABLE 5: The closeness of schemes' attributes.

\begin{tabular}{lcccc}
\hline Scheme & 1 & 2 & 3 & 4 \\
\hline 1 & 0.71 & 0.66 & 0.72 & 0.65 \\
2 & 0.38 & 0.38 & 0.48 & 0.67 \\
3 & 0.63 & 0.45 & 0.42 & 0.59 \\
\hline
\end{tabular}

TABLE 6: Calculation results of innovation schemes' attribute weights.

\begin{tabular}{lcccc}
\hline Attributes & Correlation & $\begin{array}{c}\text { Objective } \\
\text { weights }\end{array}$ & $\begin{array}{c}\text { Subjective } \\
\text { weights }\end{array}$ & $\begin{array}{c}\text { Final } \\
\text { weights }\end{array}$ \\
\hline 1 & 0.626 & 0.257 & 0.15 & 0.214 \\
2 & 0.555 & 0.228 & 0.2 & 0.217 \\
3 & 0.684 & 0.281 & 0.4 & 0.328 \\
4 & 0.571 & 0.234 & 0.25 & 0.241 \\
\hline
\end{tabular}

TABLE 7: Feasibility of the innovation schemes.

\begin{tabular}{lccc}
\hline Scheme & 1 & 2 & 3 \\
\hline Value of feasibility & 0.179 & 0.126 & 0.130 \\
\hline
\end{tabular}

an improved model to generate incremental product innovation schemes and proposes a method to evaluate the feasibility of the schemes.

Compared with other studies, this study has the following advantages: first, this study classifies the conflicts in the HoQ. Previous methods only regarded the conflicts of HoQ as technical conflicts, and physical conflicts are ignored. According to the different definitions of technical and physical conflicts, this study proposes the rules to distinguish technical and physical conflicts. Therefore, in the case study, the physical conflict among the filter replacement cycle, 
maintenance fee, and purification effect is identified and solved by the invention principle Nos. 10, 20, and 29 that form the first three measures in the first innovation scheme. Second, the integration model of QFD and TRIZ is improved. By combining the importance of part characteristic output by QFD with the Su-Field model of TRIZ, the existing product parts are improved. For example, in this case study, the TDS detection module is a new part that needs to be installed based on the analysis of the Su-Field model. However, using the previous methods, identifying the need to install a TDS detection module is difficult. Third, considering the limited resources and conditions of enterprises, solving all the problems of products simultaneously is impossible. To ensure that the incremental product innovation solves the most important problems first, equations (3) and (4) are proposed to calculate the importance of conflicts under the drive of customer requirements. Fourth, the cone model is constructed during the evaluation of innovation schemes. Attributes' weights and closeness are taken as the radius and height of the cone, respectively. The volumes of the cones are used to represent the feasibility of the scheme. The traditional methods regard one scheme with the same height, whereas the proposed method considers the difference of attributes' closeness, so one scheme has different heights. Moreover, to deal with the inadequacy and uncertainty of expert evaluation data, interval grey numbers are used by experts to evaluate the feasibility of the schemes. The generation process of the product innovation scheme proposed in this study can be used for enterprises to determine the direction of product incremental innovation.

In the process of innovation scheme generation proposed in this study, enterprises need to set up a QFD expert group and scheme evaluation expert group. The experts of the QFD group comprise the two-stage QFD matrix and determine the intangible technical conflicts and tangible part problems using the method proposed in this research. TRIZ analysis tools including contradiction matrix, separation principle, and the Su-Field model are used to analyze problems. Then, invention principles and standard solutions of TRIZ are used to solve the problems and generate innovative solutions. This process is mainly based on the experts' ability to apply QFD and TRIZ. The calculation process only involves the calculation of the importance of QFD output information and is not complicated. In addition, interval grey numbers are used by the evaluation expert group to evaluate the feasibility of the innovation schemes in the actual situation. The calculation methods used in this process include TOPSIS, GRA, and the Delphi method. Finally, the cone volume calculation formula is used to calculate the feasibility of the innovation schemes.

To adapt to the ever-changing external environment and meet customer requirements, enterprises can use the method proposed in this study to timely identify and solve the problems existing in the current products, implement incremental product innovation, and improve customer satisfaction. Moreover, the evaluation process of innovation schemes provides the basis for enterprises to make scientific decisions in the innovation process.

\section{Conclusion}

This study aims to find and identify the problems existing in products with the driving role of customer requirements and determine the most feasible innovation scheme for incremental product innovation.

6.1. Unique Contributions of the Study. To determine the problems of existing products and point out the direction for incremental product innovation, the improved integration model of QFD and TRIZ is proposed. With this model, we can effectively identify and solve the conflicts and problems existing in the technology and parts of products. Moreover, we can generate innovation schemes for incremental product innovation with the driving of customer requirements. The core of the whole process is the calculation of importance so that the solution of the priority product problems can meet the requirement of customers to a greater extent.

Considering the limitations of the product innovation scheme in the actual implementation process, the feasibility of the innovation scheme is evaluated by multiattribute to provide a basis for identifying the most feasible scheme. In the evaluation process of innovation schemes, a cone model is constructed to integrate the weights and closeness of the scheme's attributes. The volume of the cone represents the feasibility of the innovation scheme.

6.2. Managerial Implications. With the continuous learning and practice of researchers, enterprise leaders, developers, suppliers, and customers, some small improvements gradually accumulate. These improvements form significant changes in products and incremental product innovation. For enterprises, most of their developments are achieved through continuous and stable incremental innovation, which occurs more frequently and has certain predictability and low risk. Incremental innovation is an important way for enterprise and social development. Through the improved model in this research, customers' requirements can be effectively transferred to the requirements for product innovation, which determines the direction for the implementation of incremental product innovation. The multiattribute evaluation of incremental innovation scheme evaluates the feasibility of the innovation scheme from multiple perspectives, which provides a basis for the smooth implementation of the innovation scheme. This evaluation can help enterprises to reduce the risk of innovation and improve the success rate of innovation.

6.3. Limitations. The methods and model proposed in this study have some limitations. First, the improved model is built to be based on the characteristics of incremental product innovation. This model is the solution to deal with the new research problem that cannot be verified by previous 
methods. Second, the evaluation of the feasibility of the innovation scheme depends on the data provided by experts. How to evaluate through objective information is a problem to be further solved. Third, this study only evaluates the feasibility of the innovation scheme from four attributes. Additional attributes of innovation schemes should be considered under various situations in the evaluation of innovation schemes.

\section{Data Availability}

The data used to support the findings of this study are available from the corresponding author upon request.

\section{Conflicts of Interest}

The authors declare that this research was conducted in the absence of any commercial or financial relationships that could be construed as potential conflicts of interest.

\section{Acknowledgments}

This research was supported by Hebei Province Social Science Development Research Project (HB17GL048); Hebei Province Soft Science Project (20557699D and 19456217D); and Hebei University of Economics and Business Foundation Project (2019QN15).

\section{References}

[1] P. D. Stokes, Creativity from Constraints: The Psychology of Breakthrough, Springer, Berlin, Germany, 2006.

[2] D. Jugend, T. R. D. Araujo, M. L. Pimenta, J. A. Gobbo, and P. Hilletofth, "The role of cross-functional integration in new product development: differences between incremental and radical innovation projects," Innovation, vol. 20, no. 1, pp. $42-60,2018$.

[3] R. B. Bouncken, V. Fredrich, P. Ritala, and S. Kraus, "Coopetition in new product development alliances: advantages and tensions for incremental and radical innovation," British Journal of Management, vol. 29, no. 3, pp. 391-410, 2018.

[4] C.-H. Lee, C.-H. Chen, and Y.-C. Lee, "Customer requirementdriven design method and computer-aided design system for supporting service innovation conceptualization handling," Advanced Engineering Informatics, vol. 45, Article ID 101117, 2020.

[5] L. Geng, X. Shi, L. Zu, M. Chai, and J. Xing, "Importance calculation of customer requirements for incremental product innovation," Frontiers in Psychology, vol. 12, p. 2206, 2021.

[6] M. Li and J. Zhang, "Integrating Kano model, AHP, and QFD methods for new product development based on text mining, intuitionistic fuzzy sets, and customers satisfaction," Mathematical Problems in Engineering, vol. 2021, Article ID 2349716, 17 pages, 2021.

[7] L. Chechurin and Y. Borgianni, "Understanding TRIZ through the review of top cited publications," Computers in Industry, vol. 82, pp. 119-134, 2016.

[8] M. Coccia, "Sources of technological innovation: radical and incremental innovation problem-driven to support competitive advantage of firms," Technology Analysis \& Strategic Management, vol. 29, no. 9, pp. 1048-1061, 2017.

[9] A. E. Johansson, C. Raddats, and L. Witell, "The role of customer knowledge development for incremental and radical service innovation in servitized manufacturers," Journal of Business Research, vol. 98, pp. 328-338, 2019.

[10] A. B. Escrig-Tena, M. Segarra-Ciprés, and B. García-Juan, "Incremental and radical product innovation capabilities in a quality management context: exploring the moderating effects of control mechanisms," International Journal of Production Economics, vol. 232, 2021.

[11] S. Valle and D. Vázquez-Bustelo, "Concurrent engineering performance: incremental versus radical innovation," International Journal of Production Economics, vol. 119, no. 1, pp. 136-148, 2009.

[12] Y. F. Chen, Y. Ran, G. Q. Huang, L. M. Xiao, and G. B. Zhang, "A new integrated MCDM approach for improving QFD based on DEMATEL and extended MULTIMOORA under uncertainty environment," Applied Soft Computing, vol. 105, pp. 1-13, 2021.

[13] W.-C. Ko, "Exploiting 2-tuple linguistic representational model for constructing HOQ-based failure modes and effects analysis," Computers \& Industrial Engineering, vol. 64, no. 3, pp. 858-865, 2013.

[14] J. Torfing, P. T. Hart, and B. Crosby, "Public value creation through collaborative innovation," Public Management Review, vol. 19, pp. 1-15, 2017.

[15] N. T. Putri, N. Bifadhlih, and A. Sutanto, "The improvement of thresher design by using the integration of TRIZ and QFD approach," International Journal of Productivity and Quality Management, vol. 25, no. 4, pp. 459-479, 2018.

[16] M. Mayda and H. R. Borklu, "Development of an innovative conceptual design process by using Pahl and Beitzs systematic design, TRIZ and QFD," Journal of Advanced Mechanical Design Systems \& Manufacturing, vol. 8, no. 3, pp. 1-12, 2014.

[17] R. H. Tan, TRIZ and Applications: The Process and Methods of Technological Innovation, High Education Press, Beijing, China, 2010.

[18] S.-P. Wan, Z. Jin, and J.-Y. Dong, "Pythagorean fuzzy mathematical programming method for multi-attribute group decision making with Pythagorean fuzzy truth degrees," Knowledge and Information Systems, vol. 55, no. 2, pp. 437-466, 2018.

[19] S.-P. Wan, G.-1. Xu, F. Wang, and J.-y. Dong, "A new method for Atanassov's interval-valued intuitionistic fuzzy MAGDM with incomplete attribute weight information," Information Sciences, vol. 316, pp. 329-347, 2015.

[20] J.-Y. Dong and S.-P. Wan, "Max-min and min-max gray association degree-based method for multiattribute decision making," Journal of Intelligent Systems, vol. 24, no. 4, pp. 525-531, 2015.

[21] J. L. Deng, "Grey system theory and metrological futurology," Future and Deployment, no. 3, pp. 20-23, 1983.

[22] M. Hu, "Grey target decision model based on a new distance measure," Journal of Grey System, vol. 28, no. 2, pp. 27-35, 2016.

[23] X. Y. Cao and J. G. Liang, "The method of ascertaining attribute weight based on rough sets theory," Chinese Journal of Management Science, vol. 10, no. 5, pp. 99-101, 2002.

[24] J. Heidary Dahooie, S. H. Razavi Hajiagha, S. Farazmehr, E. K. Zavadskas, and J. Antucheviciene, "A novel dynamic credit risk evaluation method using data envelopment analysis with common weights and combination of multi-attribute decision-making methods," Computers \& Operations Research, vol. 129, Article ID 105223, 2021.

[25] L. Geng and L. Geng, "Analyzing and dealing with the distortions in customer requirements transmission process of QFD," Mathematical Problems in Engineering, vol. 2018, no. 10, 11 pages, Article ID 4615320, 2018. 